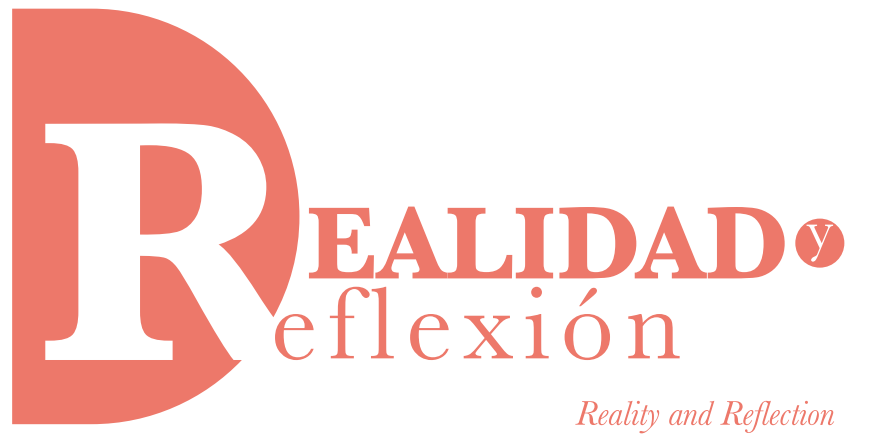

ISSN 1992-6510

e-ISSN 2520-9299

Año 19, N 49, San Salvador, El Salvador, Centroamérica. Revista Semestral Enero-Junio 2019

YEAR 19, N 49, SAN SALVADOR, EL SALVADOR, CENTRAL AMERICA. SEMESTRAL JOURNAL JANUARY-JUNE 2019

\title{
Pesetas, Calmados y Hermanos: Iniciativas de retiro, rehabilitación y reinserción de pandilleros en E1 Salvador
}

\author{
Pesetas, Calmados and Hermanos: Initiatives of \\ Desistance, Rehabilitation and Reintegration of \\ Gang Members in El Salvador
}

Luis Enrique Amaya

Lic. en Psicología por la Universidad Centroamericana “José Simeón Cañas" (UCA). Investigador asociado del Centro de Estudios Latinoamericanos sobre Inseguridad y Violencia (CELIV) de la Universidad Nacional de Tres de Febrero (UNTREF), con sede en Argentina; del Centro de Investigación y Docencia Económicas (CIDE), con sede en México, y del Instituto de Ciencia, Tecnología e Innovación (ICTI) de la Universidad Francisco Gavidia (UFG), El Salvador

leamaya@gmail.com

Juan José Martínez

Licenciado en Antropología Sociocultural por la Universidad de El Salvador (UES). Investigador asociado de la American University, de la plataforma de investigación InSight Crime y del Instituto de Ciencia, Tecnología e Innovación (ICTI) de la Universidad Francisco Gavidia (UFG), con sede en E1 Salvador.

juanjosemartinez.rds@gmail.com

Fecha de recepción: 13 de febrero de 2019

Fecha aprobación: 14 de mayo de 2019

DOI: $10.5377 /$ ryr.v49i49.8061

\section{RESUMEN}

El objetivo de este trabajo es acercarse a las vías de "retiro" de pandilleros en el país, a fin de mostrar el panorama general de las opciones existentes y describir sus características esenciales. La metodología se basa en la aplicación de dos técnicas de investigación: la revisión documental y las entrevistas en profundidad. Se exponen categorías de análisis importantes con respecto a los expandilleros, como por ejemplo las de "calmado", "retirado" y "peseta", cada una de las cuales plantea escenarios y prospectivas diferentes. Además, se explora el papel del Gobierno, el rol de la sociedad civil (incluyendo las iglesias católica y evangélica; en especial, las pentecostales), la participación del sector privado y ciertos mecanismos de las pandillas mismas. En definitiva, a todo el estudio le subyace una reflexión de carácter "identitario", por cuanto concierne a la construcción, deconstrucción y eventual reconstrucción de la identidad, a nivel personal y grupal, de los miembros y exmiembros de maras o pandillas.

Palabras clave: maras o pandillas, expandilleros, rehabilitación, reinserción, iglesias, políticas públicas. 


\section{ABSTRACT}

The objective of this paper is to approach the pathways of "desistance" of gang members in El Salvador, in order to show the general panorama of the existing options and describe their essential characteristics. The methodology is based on the application of two research techniques: literature review and in-depth interviews. Important categories of analysis are exposed with respect to former gang members, such as those of "calmado", "retirado" and "peseta", each of which proposes different scenarios and perspectives. In addition, the role of the Government, the role of civil society (including Catholic and Evangelical churches, especially Pentecostal churches), the participation of the private sector and certain mechanisms of the gangs themselves are explored. Ultimately, throughout the study underlies a consideration on "identity", as it concerns the construction, deconstruction and eventual reconstruction of the identity, on a personal and group level, of the members and ex-members of maras or gangs.

Keywords: maras or gangs, former gang members, rehabilitation, reintegration, churches, public policies.

\section{Introducción}

El presente estudio se enmarca en la agenda de investigaciones del Instituto de Ciencia, Tecnología e Innovación de la Universidad Francisco Gavidia (ICTI-UFG). Este trabajo se sitúa, en concreto, dentro de la línea de Juventud y violencia. Su objetivo fundamental es acercarse a las vías de "retiro" de pandilleros en el país, con el propósito de mostrar el panorama general de las opciones existentes y describir sus características esenciales.

La metodología se basa en la aplicación de dos técnicas de investigación: la revisión documental y las entrevistas en profundidad. Así, por un lado, se llevó a cabo el rastreo y examen de diversos documentos de referencia; y, por otro lado, se realizó un selectivo grupo de entrevistas con expertos y con miembros o exmiembros de pandillas.

En términos sencillos, el análisis del retiro o abandono de las maras o pandillas implica considerar, al menos, dos aspectos: la conceptualización del proceso y el reconocimiento o la aceptación grupal del mismo (Cruz et al., 2017). En virtud del primero, es posible identificar si una persona, luego de dejar de ser miembro "activo" de las pandillas, se ha convertido en:

- "Calmado": un miembro que simplemente ha reducido sus acciones violentas y criminales.

- "Retirado": un exmiembro que ha abandonado las pandillas y sus actividades por completo, de un modo aprobado por el grupo (usualmente por la vía de unirse a una iglesia o denominación religiosa).

- "Peseta": un exmiembro desertor, que puede llegar a atentar contra sus propios excompañeros, integrándose a otra pandilla o convirtiéndose en un informante o colaborador de las autoridades (una suerte de traidor).

El segundo aspecto, por su parte, plantea una discusión sobre quién y cómo reconoce y acepta que una persona abandone las maras o pandillas. Así como no basta que alguien se autoproclame miembro de una pandilla para transformarse automáticamente en ello, tampoco es suficiente que una persona se declare a sí misma exmiembro para inmediata y efectivamente serlo. Aunque sin duda debe mediar una decisión personal e individual, también es preciso que haya reconocimiento y hasta aceptación de otros con 
respecto a la nueva condición del exmiembro y su relación con la mara o pandilla, tanto del propio grupo como de los rivales, e incluso de los agentes del orden público.

En definitiva, a esta reflexión le subyace un asunto de carácter "identitario", por cuanto concierne a la construcción, deconstrucción y eventual reconstrucción de la identidad, a nivel personal y grupal, de los miembros y exmiembros de maras o pandillas. Tal es la complejidad que entraña la tarea de comprender e impulsar adecuadamente las iniciativas de retiro, rehabilitación $y$ reinserción de personas que pertenecen o han pertenecido en algún momento a pandillas.

\section{Tipos de actores e iniciativas}

\subsection{El papel del Gobierno}

Cuando las pandillas de origen californiano arribaron a El Salvador, a través de procesos de deportación activados a finales de los años 80 y principios de los 90, el Estado apenas se debatía entre los esfuerzos por concluir la guerra civil y los intentos por recomponerse de la misma en el marco de la transición política. Las maras o pandillas, si bien eran ya una realidad en algunos barrios marginales y centros urbanos del país, no constituían todavía un problema serio de seguridad para las comunidades o para el Gobierno. Es probable que por esta razón no se encuentren en aquella época políticas públicas o legislaciones, ni en cantidad ni calidad, que se orienten específicamente a atender ese fenómeno. Esto no significa que no se viviese un clima de inseguridad constante o que no se presentasen dinámicas de violencia generalizada (Moodie, 2012).
Las intervenciones más claras y directas datan del primer lustro del siglo XXI, cuando el expresidente Francisco Flores (1999-2004) lanza, en julio de 2003, el plan "Mano dura". En esencia, se trataba de una estrategia policial de persecución y captura de personas sospechosas de pertenecer a maras o pandillas. En ese contexto, la Asamblea Legislativa aprobó la Ley Antimaras, la que días después fue declarada inconstitucional por la Corte Suprema de Justicia (CSJ). Asimismo, el Gobierno creó 39 Grupos de Tarea Antipandillas (GTA), los cuales, además de identificar y capturar masivamente pandilleros (presuntos o probados), tenían la misión de realizar registros, allanamientos e intensivos patrullajes en comunidades con alta incidencia de delitos vinculados con el accionar pandilleril (Aguilar, 2016).

Luego de casi un año de haber iniciado la ejecución del plan "Mano dura", poco más de 17 mil jóvenes habían sido capturados por la Policía Nacional Civil (PNC), pero arriba del $80 \%$ había sido liberado en horas posteriores a su detención. ${ }^{1}$ De hecho, en ocasiones se recapturaron a las mismas personas sospechosas, por iguales motivos, para ser de nuevo liberadas tras unos días. ${ }^{2}$

En ese período, las cifras de diferentes delitos no se redujeron significativamente; por lo contrario, se presentó un efecto opuesto y los homicidios, en particular, se incrementaron. Así, El Salvador

\footnotetext{
1 Recuperado de: http://archivo.elsalvador.com/noticias/2004/07/19/ nacional/nac9.asp

2 Algunas de las fuentes consultadas para este estudio fueron aprisionadas por la Policía al menos en tres ocasiones en aquella etapa y luego puestas en libertad por jueces y juezas, quienes no podían encontrar pruebas suficientes para procesarles y condenarles.
} 
afrontó una especie de versión local de la llamada "paradoja de la represión". En palabras de Buscaglia (2013): "A esto se le denomina la paradoja de la represión: más soldados, más policías, más fiscales, más corrupción, más violencia en donde existe un círculo vicioso que conlleva a la situación actual”.

A pesar de los resultados contraproducentes, la medida gozó de exposición mediática y de la aceptación de una sociedad acostumbrada históricamente a tratar este tipo de problemas de forma violenta y represiva. ${ }^{3}$ A partir de ahí, el plan "Súper mano dura" surgió como una de las principales banderas de campaña para la candidatura de Elías Antonio Saca (20042009), lo que consolidó la apuesta por las medidas de corte represivo como eje central de las políticas de seguridad de aquellas administraciones gubernamentales. No obstante, al menos sobre el papel, la propuesta del expresidente Saca incorporaba, amén del despliegue de fuertes operativos policiales, los programas "Mano amiga" y "Mano extendida" (Cruz y Carranza, 2006).

Antes de esas fechas, las alusiones oficiales a medidas preventivas o de rehabilitación, por ejemplo, se hallaban únicamente en documentos aislados. De manera formal, la Ley del Menor Infractor $^{4}$, aprobada en 1995, introdujo la obligación legal para el Gobierno de diseñar una política específica de prevención de la violencia juvenil (Art. 127); empero, el mandato no llegó a concretarse en lineamientos palmarios. Luego

3 Entrevista con experto (San Salvador, 2016).

4 El nombre de la ley fue sustituido en 2005 por el de Ley Penal Juvenil. de eso, el Consejo Nacional de Seguridad Pública (CNSP), creado en 1996, produjo desde el arranque un conjunto de documentos programáticos, con propuestas integrales en las que se contemplaban, entre otras, acciones de orden preventivo y de reinserción social. Sin embargo, aquellas ideas iniciales del Consejo consideraban esquemas orientados a jóvenes en situación de riesgo, en un sentido lato o general, no explícitamente dirigidos a miembros o exmiembros de maras o pandillas (Consejo Nacional de Seguridad Pública, 1996; Consejo Nacional de Seguridad Pública, 1998).

Posteriormente, desde el comienzo de la administración Flores hasta su clausura en el año 2011, el CNSP asumió un rol más ejecutivo, gracias a lo cual formuló e implementó un programa de prevención social de la violencia y la delincuencia. Además, durante la administración Saca impulsó y negoció los millonarios proyectos Projóvenes I y II, financiados por la Unión Europea (UE). Y en clave de rehabilitación, las experiencias más notables de esta institución fueron dos: 1) el "Programa de Destatuaje", entre cuyos objetivos figuraba remover los tatuajes de exmiembros de pandillas que hubiesen expresado su voluntad de abandonar la violencia y demostrasen que no contaban con casos o delitos pendientes frente a la ley, y 2) la Granja-Escuela de Izalco, en la que se albergaron a pequeños grupos de expandilleros. ${ }^{6}$ Allí se

5 Para los propósitos de este trabajo lo trascendente fue el componente de remoción de tatuajes, pero el nombre exacto y oficial era Programa de Actividades Artísticas, Culturales, Deportivas, de Rehabilitación, de Investigación, de Destatuaje y de Promoción Juvenil del Proyecto de Prevención Social de la Violencia.

6 Recuperado de: https://elfaro.net/es/201105/noticias/4220/ Desaparece-Consejo-Nacional-de-Seguridad-P\%C3\%BAblica.htm 
les brindaba atención psicológica y médica, así como educación y capacitación.

Después de ello, el programa "Mano extendida", como parte del plan "Súper mano dura", fue la referencia gubernamental más evidente en materia de rehabilitación y reinserción de miembros de pandillas. En aquel momento, acerca de este programa se estableció: "Es el componente que brinda una mano extendida a los jóvenes pandilleros, en conflicto con la ley, drogodependientes o indigentes" (Cruz y Carranza, 2006). Se trataba de una mención ligeramente diluida con respecto a las maras o pandillas, situándolas entre otros grupos meta. El "Mano amiga", en cambio, estaba planteado en términos de prevención, y encauzado hacia jóvenes y comunidades en riesgo, es decir que contaba con una lógica más tradicional.

A la sazón, una circunstancia excepcional o atípica fue la creación en 2006, por parte del Gobierno, de la Comisión Nacional de Seguridad Ciudadana y Paz Social (CNSCPS), la que en el año 2007 parió el documento titulado Seguridad y Paz, un Reto de País: Recomendaciones para una Política de Seguridad Ciudadana en El Salvador. Los contenidos abarcaban acciones de prevención, rehabilitación, reinserción y la coerción contra el crimen, organizadas en 7 líneas estratégicas y 75 recomendaciones en total. No obstante, una consideración o reflexión con mayor profundidad sobre ese insumo resulta innecesaria, dado el bajo nivel de implementación operativa que alcanzó.

Con la asunción del expresidente Mauricio Funes (2009-2014) se confeccionó la Política Nacional de Justicia, Seguridad Pública y
Convivencia (Ministerio de Justicia y Seguridad Pública, 2012). Acá, las referencias a las maras o pandillas ya son más claras, sobre todo como un factor importante dentro del diagnóstico de la inseguridad en El Salvador. Se consignan estrategias y líneas de acción en los ámbitos de "Control y represión del delito" (Eje 1) y "Prevención social de la violencia y del delito" (Eje 2). En este último, se indica textualmente que se trabajará en: "Estimular el retiro de más jóvenes de las pandillas impulsando medidas de protección para evitar las represalias y reducir el temor del joven a dejar la pandilla. Al mismo tiempo, se coordinarán esfuerzos para brindar oportunidades de reinserción en la comunidad".

Como se ve, es hasta este punto que se señala de modo manifiesto en una política pública comprehensiva, probablemente por primera vez, la necesidad de atender con precisión y especificidad a las maras o pandillas, así como de "estimular el retiro" de ellas, aunque todavía no se definen vías ni mecanismos para coadyuvar a la rehabilitación y reinserción de sus miembros. Es más, durante la misma administración Funes se publicó la Estrategia Nacional de Prevención de la Violencia (Gobierno de El Salvador, 2013), y en ella solamente se apunta que la presencia de pandillas constituye un factor de riesgo para la seguridad, sin fijar líneas de acción concretas para estos grupos.

Dando continuidad a los esfuerzos de la gestión previa, la administración de Salvador Sánchez Cerén (2014-2019) elaboró la Política Nacional de Justicia, Seguridad Pública y Convivencia 2014-2019 (Ministerio de Justicia y Seguridad Pública, 2015). En este documento se aborda el fenómeno de las maras o pandillas en el apartado de "Control y represión del delito y la 
violencia" (Eje 2), como parte de una estrategia de fortalecimiento de la investigación criminal y científica del delito.

Adicionalmente, en la sección de "Rehabilitación y reinserción social" (Eje 3), la cual se centra en el sistema penitenciario, se expone el programa Yo Cambio. Esta iniciativa de tratamiento y readaptación cuenta con varios componentes complementarios, y busca que los internos se apoyen mutuamente y se transfieran entre sí experiencias y capacidades. En distintos escenarios, las autoridades han aseverado que ese programa ha tenido efectos positivos (International Crisis Group, 2017).

El Yo Cambio, empero, no está implementándose aún en todas las fases del régimen penitenciario, puesto que básicamente se aceptan reclusos de las fases de Confianza y de Semilibertad. La inclusión de privados de libertad de la fase Ordinaria únicamente ha ocurrido en algunos centros penales. Sin embargo, la limitación más visible es que el programa, junto con las Granjas penitenciarias, no se está ejecutando en la totalidad de centros de seguridad en los que guardan prisión los miembros de maras o pandillas. Sólo en ciertos casos puntuales se ha iniciado su implementación, como en los centros penitenciarios de San Francisco Gotera, Chalatenango y Ciudad Barrios, y en sectores de Ilopango y Quezaltepeque. ${ }^{7}$ De hecho, la experiencia en la cárcel de San Francisco Gotera admite matices, ya que ahí hubo más de 400 pandilleros que tomaron la decisión unilateral de abandonar la facción Revolucionarios del Barrio

7 Recuperado de: https://elfaro.net/es/201901/el_ salvador $/ 22802 / \% \mathrm{E} 2 \% 80 \% 9 \mathrm{CYo}$-estoy-convencido-de-que-lospandilleros-se-pueden-rehabilitar\%E2\%80\%9D.htm
18 para vincularse a una iglesia. ${ }^{8}$ En suma, la participación de miembros de maras o pandillas en el programa Yo Cambio todavía es baja y parcial. Son apenas una minoría en la población atendida, por lo que los resultados a obtener con ese grupo son imponderables a la fecha.

Con todo,la estrategiainsignia dela administración Sánchez Cerén es el Plan El Salvador Seguro (Consejo Nacional de Seguridad Ciudadana y Convivencia, 2015). Esta propuesta fue diseñada por el Consejo Nacional de Seguridad Ciudadana y Convivencia (CNSCC), una instancia de coordinación interinstitucional y articulación multinivel creada en 2014 por el presidente de la República, en cuyo seno confluyen actores de diverso signo, incluyendo el Gobierno nacional, la empresa privada, iglesias, organizaciones de la sociedad civil, medios de comunicación, los partidos políticos y el sector justicia.

En ese documento se reconoce que la "afinidad a grupos de pandillas"; es decir, tener amigos cercanos que sean pandilleros, representa un factor de riesgo decisivo para niños y jóvenes. Y, en tal sentido, se asume la tarea de: "Revisar la Ley de Proscripción de Maras, Pandillas, Agrupaciones y Organizaciones de Naturaleza Criminal, para que puedan insertarse socialmente aquellos miembros que quieran salir de estos grupos". Aunque la alusión a la (re)inserción de miembros de pandillas es más directa, sigue siendo tímida y marginal en el conjunto del plan.

La Ley de Proscripción de Maras ${ }^{9}$, aprobada en

8 Recuperado de: https://elfaro.net/es/201704/salanegra/20223/Larevoluci\%C3\%B3n-de-las-ovejas.htm

9 El nombre completo es Ley de Proscripción de Maras, Pandillas, 
2010, obliga al Estado salvadoreño a establecer una "normativa especial" con respecto a “... las condiciones de retiro o deserción y rehabilitación de los miembros de las agrupaciones, asociaciones y organizaciones criminales de las que trata la presente Ley". Es a eso a lo que también se comprometió, entre otras cosas, el CNSCC. No obstante, a la fecha aún no se dispone de un marco legal que facilite y guíe las iniciativas en esta materia.

Hasta ahora, el Ministerio de Justicia y Seguridad Pública (MJSP) ha presentado un anteproyecto titulado Ley Especial para la Prevención, Rehabilitación y Retiro de Miembros de Maras o Pandillas (Fundación de Estudios para la Aplicación del Derecho, 2018). Otras fuentes lo refieren con un nombre diferente: Ley Especial de Reinserción de Miembros de Pandillas y de Prevención para Personas en Riesgo. ${ }^{10}$ Asimismo, partidos políticos como ARENA y PDC han elaborado y entregado sus propios anteproyectos de ley. Empero, ninguna propuesta ha prosperado $y$, en consecuencia, el país no tiene actualmente un instrumento jurídico apropiado.

En síntesis, a lo largo de los años, el Gobierno de E1 Salvador ha logrado transformar el discurso relativo a las maras o pandillas, con más fuerza en el ámbito de la represión y el control del delito. La inclusión de ese fenómeno en las estrategias oficiales de abordaje de la inseguridad ciudadana ha sido lenta y paulatina, cuando menos con la claridad debida o esperada. A pesar de ello,

Agrupaciones, Asociaciones y Organizaciones de Naturaleza Criminal.

10 Recuperado de: https://elfaro.net/es/201504/noticias/16907/ Gobierno-tiende-la-mano-por-primera-vez-a-quienes-quieranabandonar-pandillas.htm en lo tocante a la rehabilitación y reinserción el cambio de discurso no ha sido tan expreso, y menos patente todavía es la modificación en las prácticas institucionales en esta línea. De entrada, la carencia de una base legal adecuada deja en vilo cualquier esfuerzo que se emprenda, tanto gubernamental como no gubernamental, aunque solucionar eso no depende sólo del Órgano Ejecutivo.

Es posible que una de las vías estatales más efectivas para provocar el abandono de las pandillas haya sido la utilización del "criterio de oportunidad”, regulado en el Código Procesal Penal, por parte de la Fiscalía General de la República (FGR). Este recurso legal puede ser entendido como una de las técnicas especiales de investigación del delito. En palabras de Mendoza y Pacheco (2015): “Corresponde, entonces, hablar sobre el criterio de oportunidad por colaboración con la justicia, o denominado también justicia premial, como instrumento procesal aplicado a raíz de la reforma de código procesal penal que entra en vigencia en el año de dos mil nueve, para el combate de la delincuencia organizada”.

El "criterio de oportunidad" es una herramienta clave para investigar y probar hechos graves, como por ejemplo de crimen organizado, en virtud de las dificultades que exhibe la consecución de elementos que comprueben en un juicio la existencia de ciertas organizaciones delictivas, la pertenencia de sus integrantes activos y la operatividad criminal de los mismos. De esa manera, gracias a la FGR, los miembros de maras o pandillas pueden convertirse en "testigos criteriados", aportando información valiosa de las actividades de sus grupos a cambio 
de recibir beneficios procesales, con lo cual, en la jerga pandilleril, se hacen "pesetas".

Así, colaborar con las autoridades del sistema de justicia penal podría ser un camino para salir o abandonar las pandillas, pero supone pagar el alto costo de ser un enemigo jurado de los propios excompañeros, ser permanentemente perseguido por ellos y cargar con una indeleble condena de muerte.

\subsection{El rol de la sociedad civil ${ }^{11}$}

De acuerdo con estudios anteriores, la mayor parte de organizaciones no gubernamentales (ONG) del país nacieron en el período de la guerra civil, y suplieron las limitaciones del Estado en distintas esferas de política pública (Cruz, 2006). Sin embargo, en materia de seguridad ciudadana el trabajo de las ONG se ha enfocado, predominantemente, en proyectos de prevención social de la violencia, no tanto de rehabilitación y reinserción de personas en conflicto con la ley.

En retrospectiva, para la década de los años 90 había un abanico de temas de los que se ocupaban las ONG, convergiendo la mayoría en el estratégico asunto del "desarrollo". Pese a ello, como afirmaba Foley (1995), no había suficiente claridad ni consenso sobre las implicaciones de ese concepto y cada organización operaba según su visión y sus propias líneas de acción. Algo similar puede decirse que sucede en este

11 En el apartado concerniente a la sociedad civil, producto de la revisión histórica, se podrían consignar otras experiencias, dentro de las que descollaría un proyecto de la Fundación San Andrés. Esta iniciativa estaba encabezada por Ernesto Miranda, alias "Smokey", fundador de la MS-13 en Los Ángeles, quien fue asesinado en 2005. No obstante, no se pudo acceder a datos pormenorizados sobre esa intervención. momento con la temática de la prevención de la violencia y la delincuencia (primaria, secundaria y terciaria), lo que ha redundado en una atomización y desarticulación de las iniciativas incoadas por las $\mathrm{ONG}$ en ese ámbito.

Al interior de la sociedad civil, otro actor protagónico han sido las iglesias, particularmente las evangélicas. Según ciertos autores, el florecimiento de las iglesias evangélicas en El Salvador ocurrió en el contexto de la guerra civil y fueron fundadas, en buena medida, con influencia de iglesias estadounidenses (Brenneman, 2012). También crecieron las iglesias bautistas y pentecostales en aquel período (Monroy, 1996). Su contribución y trabajo directo con miembros y exmiembros de maras o pandillas amerita una revisión aparte.

A continuación, se muestran a grandes rasgos algunas experiencias de rehabilitación y reinserción que vale la pena tener en cuenta, las cuales han sido impulsadas por instancias y agencias diversas, con base en metodologías distintas y, por ende, con potencialidades diferentes.

\subsubsection{Homies Unidos: pandilleros "no activos en violencia"}

Homies Unidos es una organización de miembros de pandillas "no activos en violencia" que comenzó operaciones en El Salvador en 1996, fundamentalmente con pandilleros deportados de Estados Unidos. En su mayoría eran miembros del Barrio 18, aunque había algunos de otras pandillas sureñas e incluso de la Mara Salvatrucha 13 (MS-13).

Estos pandilleros se unieron con varios objetivos, entre los cuales estaban el cambio de estilo de 
vida, la generación de nuevas oportunidades y la defensa de los derechos humanos de pandilleros y población privada de libertad. No se trataba, primordialmente, de muchachos adolescentes en busca de aventura, sino de hombres jóvenes, alrededor de los 30 años de edad, que querían alejarse de la violencia y de la dinámica de las calles para poder "empezar de cero".

Al comienzo, la iniciativa tuvo respaldo de organismos internacionales, como la organización Cordaid de Holanda. Participaron activamente, como una especie sui géneris de asesores o equipo de campo, en las primeras investigaciones destacables que exploraron el fenómeno de las maras o pandillas en el país (Smutt y Miranda, 1998; Cruz y Portillo, 1998; Santacruz y ConchaEastman, 2001). La colaboración de Homies Unidos fue parecida en todos los estudios. Su función era abrir puertas con pandilleros dentro de los barrios y los centros penales, servir de enlace con fuentes de información y recoger ellos mismos datos en terreno.

Este grupo de pandilleros no activos o "calmados", a pesar de gozar de reconocimiento y hasta de financiamiento internacional, al menos al principio, tuvo dificultades para constituirse formalmente, ya que el Ministerio de Gobernación retuvo por varios años el proceso de inscripción y acreditación de su personería jurídica, a tal grado que en 2007 (es decir, 11 años después de haberlo solicitado) todavía esperaban la materialización del trámite.

Además de contribuir con la realización de investigaciones académicas, Homies Unidos implementó algunos programas de apoyo para jóvenes pandilleros que deseaban transformar sus vidas. En esa línea, por ejemplo, proveyeron ayuda financiera para el montaje de pequeños emprendimientos y desarrollaron proyectos temporales de remoción de tatuajes.

Sin embargo, su trabajo se vio seriamente cuestionado cuando uno de sus directores, José Heriberto Henríquez, alias "Eddie Boy"12, fue arrestado y condenado por participar en el homicidio en 2005 de José Luis Cortez Guerrero, "el Cranky", líder del Barrio 18, producto de riñas internas entre las figuras de poder de esa pandilla (Amaya y Martínez, 2015). Tiempo después, en 2009, fue asesinado el periodista franco-español Christian Poveda, quien realizó una película documenta ${ }^{13} 1$ sobre la pandilla Barrio 18 de la colonia La Campanera, en Soyapango, y cuyo enlace también fue Homies Unidos.

Los integrantes activos de esta organización variaron en el transcurso de los años y dependiendo de los contextos. Luis Romero, un viejo pandillero del Barrio 18 conocido como "Panza Loca", administró lo que quedó de los buenos tiempos de Homies y aún daba entrevistas a periodistas e investigadores internacionales. Romero falleció en un accidente de tránsito en octubre de $2016 .{ }^{14}$ En la actualidad, sus oficinas han cerrado y no mantienen vigente ninguno de sus proyectos originales.

Homies Unidos en El Salvador se creó bajo la inspiración de la institución californiana del

\footnotetext{
12 Recuperado de: https://salanegra.elfaro.net/es/201110/ cronicas/5645/Todas-las-muertes-del-Cranky.htm
}

13 El título del documental es La Vida Loca.

14 Recuperado de: http://www.elsalvadortimes.com/articulo/ sucesos/muere-expandillero-fundador-organizacion-hommiesunidos/20161004100804009047.html 
mismo nombre, la cual dirige desde hace más de 10 años el expandillero de la MS-13 Alex Sánchez. Empero, tal como pasó con las pandillas, estas sucursales no tardaron en desligarse y tomar caminos distintos. En el país, la iniciativa estuvo conducida desde el arranque por Magdaleno Rose-Ávila, quien tuvo muchos problemas al tratar de juntar a pandilleros de diversas agrupaciones, como lo exponen algunas fuentes:

Nos llevaron a un convivio allá a un lago. Nos dieron charlas y que comamos y que convivamos. Yo iba con otro homeboy de la mara cuando el bijueputa de nombre de un miembro de la pandilla rival] se quiso subir a la lancha donde nosotros íbamos a pescar. 'Vaya, si ese cerote se sube, con la misma caña le voy a zampar, ¿̇oiste?', le dije a mi homeboy. Cabal, se subió y le dejo ir el cañazo al bijueputa y abi se armó gran desvergue. ${ }^{15}$

Si bien este tipo de discordias interpersonales eran de esperarse, dada la naturaleza de los grupos pandilleriles, también se presentaron conflictos más delicados, tal como lo recuerda un exdirigente de Homies:

Una vez llegaron los MS, emputados porque no les quisimos dar cabida, no quisimos que se quedaran al frente de la institución. La onda es que tiraron una papa [granada hechiza], luego como 4 balazos. Ahí hirieron a una chica en la pierna, le rompieron el hueso, y después de eso ya fue bien difícil que ellos tuvieran llegada ahí. Fue quedando en manos de los $18 \mathrm{y}$ de pandilleros sureños después de ese desvergue. ${ }^{16}$

15 Entrevista con pandillero retirado (San Salvador, 2014).

16 Entrevista con pandillero retirado (San Salvador, 2016).
Wolf(2012), quien realizó un estudio posdoctoral de varios años con Homies Unidos, sostiene que la organización se vio superada de cierta manera por las complicaciones derivadas de estar conformada exclusivamente por pandilleros. La insistencia de sus dirigentes de no contratar personal que no hubiese tenido un probado pasado pandilleril significó un lastre para su crecimiento técnico como institución. Por otro lado, descubrió que los programas de prevención $y$ rehabilitación no fueron consistentes $y$ terminaron difuminándose, producto de apuros financieros y del poco compromiso de los participantes para cambiar su vida. Y, por último, concluye que los problemas que muchos de ellos arrastraron, desde sus años como miembros activos de maras o pandillas, acabaron minando la proyección institucional.

\subsubsection{La iglesia católica y su trabajo con pandilleros}

La religión, y más en específico la religiosidad, está presente de un modo notorio en sectores variopintos de las sociedades centroamericanas, prácticamente desde la época precolombina (Montes, 1979). De hecho, en El Salvador las encuestas suelen situar a las iglesias, tanto la católica como las evangélicas, en los primeros lugares de las instituciones que inspiran mayor confianza en la ciudadanía, por encima de todas las demás (Instituto Universitario de Opinión Pública, 2018).

Es más, cuando en el año 2012 se impulsó "la Tregua” entre pandillas (Katz \& Amaya, 2015), auspiciada por el Gobierno, un elemento clave para que la opinión pública, la oposición política $\mathrm{y}$ otros actores nacionales no se lanzaran en 
contra del proceso fue el involucramiento de un sacerdote católico, Mons. Fabio Colindres, a la sazón Obispo Castrense. Todo apunta a que fue esta figura la que, con su mera presencia, precisamente dotó de algún nivel de legitimidad a aquel experimento gubernamental.

Como explican algunos autores (Brenneman, 2012; Montes, 1979), el factor religioso juega un rol mediador y fuertemente identitario en la cosmovisión de las poblaciones de la región, e incluso de los miembros de maras o pandillas. En este punto, dos experiencias merecen ser descritas.

\subsubsection{Polígono Industrial Don Bosco}

El Polígono Industrial Don Bosco viene ejecutando proyectos sociales desde finales de la década de los años 80, pero es en 1996 cuando establece un programa dirigido a la juventud en riesgo y en conflicto con la ley. ${ }^{17}$ Ahí empieza decididamente su trabajo orientado a brindar herramientas y oportunidades a jóvenes pandilleros.

Los dos ejes cardinales de estos esfuerzos han sido: 1) proyectos vocacionales, en donde se capacita a jóvenes en trabajos prácticos y oficios (panadería, carpintería, mecánica, zapatería, etc.), y 2) proyectos educativos, entre cuyos propósitos se halla que los participantes completen los currículos formales que exige el Ministerio de Educación (MINED), a través del otorgamiento de becas de estudio, la impartición de clases en horarios extraordinarios o flexibles y la oferta de programas de formación a distancia.

17 Recuperado de: https://distintaslatitudes.net/pandillas-en-elsalvador-el-caso-de-la-iberia-un-modelo-exitoso-de-prevencion
Esta intervención representa una de las experiencias más explícitas y sin rodeos de atención directa a miembros de maras o pandillas. Asimismo, en un sentido positivo, los proyectos del Polígono Don Bosco se localizan físicamente en una comunidad muy conflictiva y afectada por la violencia pandilleril: La Iberia. ${ }^{18}$ Sin embargo, sucede que esto también conlleva peligros, $y$ ya ha habido casos de acoso a expandilleros mientras se trasladan o salen de las instalaciones. Es el efecto de lo que en otras latitudes se da en llamar "fronteras invisibles", lo cual entorpece la movilidad de las personas, debido a que las relativas seguridades que pueden sentirse $y$ tenerse dentro de las comunidades de residencia se pierden al salir de ellas, y se corre el riesgo de sufrir amenazas de pandillas rivales ubicadas en territorios próximos (Amaya y Martínez, 2014).

Es probable que la debilidad potencial más crítica de esta iniciativa esté asociada con el rol determinante que juega su fundador, el padre José "Pepe” Moratalla. Según Cruz (2006), casi todas las responsabilidades recaen en esta figura y, a su vez, están atadas a su cargo y presencia personal. Eso podría dificultar la permanencia de los proyectos a largo plazo. Con todo, no se pretende aquí hacer, ni por asomo, una evaluación rigurosa del impacto o la sostenibilidad del Polígono Industrial Don Bosco.

\subsubsection{El CFO y su proyecto laboral}

En 2009 abrió sus puertas un proyecto novedoso de la Congregación Pasionista en

18 En esta comunidad hay presencia tanto de la MS-13 como del Barrio 18. No obstante, el lugar en el que se encuentra el Polígono Don Bosco está bajo dominio de la clica Iberia Locos Salvatruchos (ILS) de la MS-13. 
el municipio de Mejicanos. Se le denominó "Centro de alcance" y se ubicó en una zona con alta presencia de pandillas: La Montreal. En concreto, el proyecto funcionaba en la colonia Buenos Aires, lugar donde opera desde finales de los años 90 la clica Guanacos Criminales Salvatrucha (GCS) de la MS-13.

Esta iniciativa fue promovida desde el Centro de Formación y Orientación Padre Rafael Palacios (CFO) fundado por sacerdotes pasionistas y vinculado a la iglesia católica. En esencia, se aspiraba a construir un espacio donde los jóvenes pudiesen reunirse, hacer tareas, utilizar computadoras e internet, tener acceso a material didáctico y, a la vez, recibir talleres artísticos y diversas charlas. El financiamiento provenía en buena medida de Brücke - Le pont, una organización de cooperación suiza.

El "Centro de alcance", si bien sobre el papel estaba dirigido a jóvenes en general, en la práctica se destinó a jóvenes pandilleros activos. El principal encargado, el padre Antonio "Toño" Rodríguez, designó a un novel exseminarista para regentar el proyecto y educar en cultura de paz a los pandilleros que decían buscar la rehabilitación y reinserción.

La acción más notable fue el montaje de una panadería, pensada para albergar al menos a medio centenar de jóvenes pandilleros y volverse con el tiempo una empresa rentable. Para ello, se les dio capacitación, se equipó el local con un horno y todos los implementos necesarios para la fabricación de pan y se brindó asistencia técnica por parte de una panadera certificada.

Este proyecto fue minuciosamente examinado en el marco de un estudio etnográfico efectuado durante todo el año 2010, justamente dentro de la colonia Buenos Aires (Martínez, 2013). La idea de la panadería surgió de conversaciones entre el padre "Toño" y un miembro veterano de la pandilla del lugar, Giovanni Morales, alias "Destino", quien había recobrado su libertad en noviembre de 2009, luego de pasar una década en prisión. De hecho, Rodríguez rápidamente dejó a Morales a cargo de la panadería, con la misión de involucrar a más pandilleros.

Para febrero de 2010, el proyecto contaba con no menos de 7 participantes, pandilleros jóvenes que sondeaban la opción de la reinserción. Al cabo de 3 meses, la panadería ya estaba abasteciendo a buena parte de las tiendas cercanas y a algunos vendedores ambulantes. Giovanni Morales, por ser un miembro reconocido de la pandilla, gozaba de cobertura y de ascendencia entre los pandilleros novatos. Por esa razón, pudo atraer a algunos de ellos hacia el proyecto. Empero, los integrantes más jóvenes de la clica GCS se sentían cautivados por la posibilidad de comer pan gratis y escuchar las historias que Morales relataba acerca de los orígenes de la MS-13, no tanto por las oportunidades de rehabilitación que se ofrecían. La afluencia efectiva siempre avanzó a medio gas.

En mayo de 2010, pocos meses después de la apertura, el "Centro de alcance" y su panadería habían consolidado su transformación en una suerte de destroyer o "casa de seguridad" para los jóvenes pandilleros. Solamente Morales y otro pandillero expresidiario continuaban haciendo pan. El local era usado por los miembros activos de la GCS para reunirse, planificar atentados contra sus enemigos, esconder armas o drogas y 
hasta llevar a cabo sus complejos rituales internos de iniciación y castigo.

Así fue hasta que ocurrieron los eventos de junio de 2010, cuando pandilleros del Barrio 18 quemaron vivas en una buseta a 17 personas que residían en La Montreal, comunidad controlada por la MS-13 (Moodie y Martínez, 2015). Eso constituyó un punto de quiebre para las dinámicas pandilleriles de aquella área geográfica y la casa de los pasionistas definitivamente dejó de funcionar como se planificó, sin retorno.

Giovanni Morales, el "Destino”, fue asesinado en marzo de 2013 frente a las oficinas del Servicio Social Pasionista en Mejicanos. Inmediatamente, aparecieron diferentes hipótesis sobre el hecho. Una de ellas, la que difundieron los mediadores de "la Tregua", señalaba a grupos de policías y militares que buscaban socavar aquel proceso de “pacificación”. No obstante, otra teoría apuntaba al interior de la misma MS-13. Algunos informantes de esta investigación afirman que el homicidio de Morales fue una consecuencia del rol que jugó en iniciativas de reinserción de pandilleros durante años. Fuese como fuese, el caso quedó impune, por lo que resulta imposible a día de hoy tener certeza de los culpables y sus objetivos.

\subsubsection{Homies en Cristo: puerta de salida desde el pentecostalismo moderno}

A medida que progresaba el trabajo de campo para este estudio, el equipo advirtió una marcada tendencia hacia el fervor religioso de corte pentecostal entre los pandilleros retirados que fueron contactados. Es más, varios de ellos atribuyen su salida de la vorágine de las violencias pandilleriles a un acercamiento con alguna iglesia de esta denominación. Los enlaces claves han sido, precisamente, pastores evangélicos cuyas pequeñas iglesias labraron una reputación dentro de los barrios. Sus estrategias de rehabilitación y reinserción, ciertamente, se aproximan más a procesos de conversión espiritual y salvación personal que a proyectos de desarrollo social.

Esta especie de "alianza no explícita” entre maras o pandillas e iglesias evangélicas pentecostales tiene su explicación, probablemente, en el hecho de que ambas agrupaciones comparten una serie de similitudes sociológicas, incluyendo su raigambre socioeconómica y la manera en la que se edifica y sostiene su identidad grupal.

\subsubsection{Pandilleros y pentecostales: dos hijos del mismo proceso}

Las iglesias evangélicas tocaron suelo salvadoreño en la segunda mitad del siglo XIX, en el contexto de la crisis provocada por la instauración del Estado laico en la región centroamericana, la ruptura entre las élites burocráticas y una burocracia católica que todavía guardaba fuertes vestigios coloniales (Lara, 1996). Esto generó un clima propicio para que iglesias evangélicas, mayoritariamente de origen estadounidense (Brenneman, 2012), tuvieran una ventana para zambullirse en el campo religioso de la gente.

El concepto de campo religioso, en este caso, es retomado de Bastián (1986), y básicamente tiene que ver con las relaciones entre los distribuidores y los consumidores de bienes simbólicos de "salvación", por un lado; y, por el otro, los productores de los mismos, quienes mantienen una constante competencia por conservar la hegemonía en un contexto histórico particular. 
Las primeras iglesias que tuvieron presencia en este campo fueron, aunque pocas, muy diversas. Destacan sobre todola Misión Centroamericana, pentecostales independientes, Bautistas Americanos y la Sociedad Bíblica Americana (Huezo Mixco, 2013). A pesar de la fractura en los vínculos de poder entre el Estado y la iglesia católica, la sociedad en general estaba aferrada a una tradición católico-romana y estas iglesias de procedencia norteamericana no fueron muy bien recibidas por las élites. Sin embargo, según Vega (2013), tuvieron cierta aceptación entre la población indígena del occidente, una región que para entonces concentraba a gran parte de la población salvadoreña, debido a sus condiciones económicas ligadas a la producción del café. Existen registros que reportan, por ejemplo, que la Misión Centroamericana logró fundar algunas iglesias y establecer cultos de forma sistemática en las faldas del volcán de Santa Ana.

Con todo, en el campo religioso la preeminencia seguía teniéndola claramente la iglesia católica. Esto se expresó en acciones de rechazo por parte de segmentos católicos de las comunidades donde llegaron las iglesias evangélicas. Lara (2006) recoge un testimonio ilustrativo de un pastor evangélico en 1940:

Al principio, si que, cuando eso, viera, cómo sufrimos, pedradas, porque decian ellos que nosotros éramos de otra religión, nos apedrearon, venían unos jóvenes, mayores, le rompian, le tiraban en la cara y nos apedrearon bastante tiempo.

El mismo autor, en entrevista, aseveró que es hasta principios de los años 70 que las iglesias evangélicas ingresan al campo religioso de modo masivo:

\section{Los evangélicos entran a El Salvador en realidad en la década de los setentas, cuando se da una apertura producto del proceso revolucionario de transformación sociocultural. ${ }^{19}$}

Esta apertura tuvo ecos en la economía, en la política y por supuesto en el ámbito religioso. Hay que recordar que en ese período se dio una segunda ruptura de la iglesia católica con la burocracia estatal, y con sectores de la élite burguesa y aristócrata, a raíz de una nueva ola reformista interna incoada con el Concilio Vaticano II, el surgimiento de la Teología de la Liberación y el nacimiento de las Comunidades Eclesiales de Base. Estas últimas, en torno a una interpretación marxista del Evangelio, aglutinaron a masas de campesinos inconformes no sólo con un modelo económico que cristalizó en desigualdad social, sino con todo un sistema político y cultural que los mantenía al margen del desarrollo (Montes, 1979). A la postre, esto coadyuvó al devenir de la guerra civil en El Salvador.

En ese momento, una vez más, muchas iglesias bautistas, pero en mayor cantidad pentecostales, arribaron al país. Para algunos investigadores, el repentino auge de las iglesias evangélicas en el marco del conflicto armado estaba apadrinado por el Gobierno de Estados Unidos, como un componente de su estrategia para frenar el movimiento revolucionario que venía robusteciéndose. ${ }^{20}$ Desde esta especulación, esas

19 Entrevista con experto (San Salvador, 2016).

20 Entrevista con experto (San Salvador, 2016). 
"misiones de fe" tenían por finalidad convertirse en una alternativa apolítica dentro del campo de lo religioso, con el objeto de restarle vigor a la movilización popular de protesta que, según se percibía, estaba acompañada por la iglesia católica.

Independientemente de que fuera una estratagema contrainsurgente o se tratara de un proceso sociocultural “natural”, los pentecostales y bautistas continuaron creciendo, desarrollándose e hibridándose con las expresiones religiosas locales. Esa versatilidad ha sido, posiblemente, uno de los factores más relevantes que viabilizaron su expansión, puesto que permitía a las poblaciones incorporar sus cosmovisiones, creencias y toda su cultura religiosa a una nueva forma de vida espiritual.

La MS-13 y la pandilla Barrio 18 de E1 Salvador, aunque la aserción pueda sorprender, tuvieron trayectorias con importantes parangones respecto de las iglesias evangélicas. Como los bautistas y pentecostales, esas pandillas también tienen su cuna en Estados Unidos. Los primeros pandilleros deportados arribaron al país en un entorno de mutación sociocultural aguda: el fin de la guerra civil y el inicio del proceso de democratización, en donde se vuelven una opción alejada de la política para buena parte de la población, sobre todo para los jóvenes.

Las maras o pandillas encuentran su nicho prácticamente en los mismos lugares en los que, casi 20 años atrás, se había instalado la mayoría de iglesias bautistas y pentecostales: los barrios y las comunidades marginales. De hecho, en esos sitios habitaban poblaciones de extracción campesina, mismas que fueron más receptivas con las iglesias evangélicas en sus albores y que provenían de áreas rurales del interior, como resultado de amplios desplazamientos internos a causa de la guerra.

Además, sin verbalizarlo expresa y conscientemente, y tal vez sin una reflexión articulada y sopesada, estos grupos proponen un sistema de relaciones sociales bastante similar.Las iglesias, al igual que las pandillas, se convirtieron en un mecanismo social para adquirir una posición de respeto en el microcosmos de los barrios. En otras palabras, ambas estructuras constituyen una senda para que una persona pueda volverse alguien socialmente notable, a través de la pertenencia y la entrega total a un grupo (Brenneman, 2012).

Por otro lado, las iglesias evangélicas también se ven rechazadas al inicio por círculos de poder religioso, por cuanto se les observó como una amenaza a posiciones tradicionales dominantes. Parecida fue la marginación enfrentada en su momento por los miembros de maras o pandillas, en especial por parte de grupos juveniles $y$ bandas organizadas existentes desde los años 80. Y, asimismo, en esos entornos hostiles, los pandilleros, así como los evangélicos, tuvieron una enorme capacidad de adaptación a contextos socioculturales novedosos, lo que les obligó a incorporarse y participar del universo simbólico de las poblaciones.

Obtener un número exacto de iglesias bautistas y pentecostales es muy difícil, debido a su autonomía respecto a una estructura vertical. $\mathrm{Su}$ organización en "células", como figuras fractales, es uno de sus rasgos característicos. Normalmente, son manifestaciones locales, a veces efímeras, que brotan en el seno mismo 
de barrios y comunidades. Algo similar sucede con las clicas de las pandillas. Esa relativa autonomía es la que les permite acercamientos y convergencias entre ambas agrupaciones.

En el caso de las iglesias bautistas y pentecostales, a diferencia de las experiencias detalladas previamente, no se descubren sofisticadas metodologías de trabajo en materia de rehabilitación y reinserción de miembros de maras o pandillas, con referencias técnicas o respaldos internacionales. Por 10 contrario, sus intervenciones descansan en un contacto cotidiano y permanente con los jóvenes, enmarcado en procesos de "sanación" o expiación y "cooptación de almas", es decir, como una dimensión de su misión espiritual, no como actividades de desarrollo social en sentido estricto.

Empero, amén de proveer de ambientes propicios para el drenaje catártico o emocional, lo que podría tener eventuales efectos terapéuticos a nivel afectivo y sentimental, estas iniciativas también representan una ayuda para recomenzar la formación de un nueva, nutrida y sólida red social de apoyo. Esto permite reconstruir las relaciones familiares y comunitarias, lo que llena vacíos y necesidades psicológicas decisivas, no tanto las de orden material.

Adicionalmente, los esfuerzos de reinserción de pandilleros que impulsan las iglesias evangélicas ofrecen un camino para continuar siendo "alguien" en sus propios entornos comunitarios. Muchos jóvenes hallan respeto y un asidero para su autoestima al ingresar a las maras o pandillas (Cruz et al., 2017), y las iglesias bautistas y pentecostales brindan la oportunidad de mantener una posición de estatus y reconocimiento social, lo cual tiene valor y peso específico.

\subsection{El sector privado}

Dentro de la empresa privada no es frecuente dar con iniciativas que abran espacios a miembros y exmiembros de maras o pandillas. No obstante, hay una experiencia que, por su unicidad, resulta indispensable describirla.

\subsubsection{League Collegiate Outfitters: una iniciativa integral}

League Collegiate Outfitters es una empresa dedicada a la fabricación de ropa deportiva para universidades estadounidenses, cuyas oficinas se localizan en el Parque Industrial American Park. Dispone de más de una decena de programas de Responsabilidad Social Empresarial (RSE) y cuenta con varios centenares de empleados, $17 \%$ de los cuales fueron miembros activos de pandillas en el pasado (Soler y Flores, 2016).

En palabras de un expandillero de la MS-13: Es como la cueva de Adulam, donde llegaban los deudores y ladrones y gente perseguida. Asi es acá. ${ }^{21}$

En la Biblia, la "cueva de Adulam" es sinónimo de refugio. Y es que los programas de RSE de League incluyen acciones en ejes temáticos complementarios, tales como: familia, educación, vivienda, emprendedurismo, medioambiente $\mathrm{y}$ espiritualidad, entre otros. Los exmiembros de maras o pandillas pueden participar en todos ellos, sin excepción. Esto plantea un desafío

21 Entrevista con pandillero retirado (Ciudad Arce, 2016). 
para la convivencia en la empresa, el cual ha sido manejado sin inconvenientes. ${ }^{22}$

En el curso de las entrevistas, los pandilleros retirados explicaron cómo entraron a sus grupos pandilleriles. Las motivaciones van desde la búsqueda de estatus, prestigio y aventura, típicamente entre hombres, hasta la necesidad de protección contra acoso, intimidaciones o maltratos, más usual entre mujeres, aunque no parecen ser circunstancias excluyentes en virtud de género.

Como denominadores comunes, subyacen situaciones de abandono familiar y falta de oportunidades para el desarrollo personal. La pandilla les acoge y brinda posibilidades de crear otra versión o imagen de sí mismos, la que les permite sentirse orgullosos, generar un sentido de identidad afincado en la pertenencia al grupo y en la relación de oposición radical con el otro antagónico. Incluso les dota de una suerte de aciago "proyecto de vida", porque se visualizan a futuro escalando peldaños de poder e incrementando su reconocimiento dentro de la agrupación.

A medida fueron conociendo con más profundidad el interior de sus respectivos grupos y sus dinámicas e intrigas intestinas, la mal llamada "política" (Blatchford, 2011), fueron desencantándose y comenzaron a tener otras necesidades personales, desde afectivas y sociales hasta económicas, las que la pandilla no podía satisfacer. Sin embargo, cuando cayeron en la cuenta, estaban tan inmersos que ya era muy complicado contemplar una separación serena.
Desde otra perspectiva, se detecta el impacto del recambio generacionalen las maras o pandillas. Los exmiembros entrevistados, quienes se consideran parte de "la vieja escuela", no comparten lo que, a su juicio, son los nuevos valores de las pandillas. Rememoran con añoranza los años 90, cuando la pandilla todavía era entendida como una especie de "familia", en contraposición al ideario actual, que es más afín a una concepción y visión de "negocio". Una pandillera retirada lo relata:

Es que en mi generación eran otros valores al interior de la pandilla. No existía eso de que si vos vas para arriba yo voy a ver cómo te jodo. Vivíamos en la comunidad y la cuidábamos, era una forma de protegernos de otras pandillas $y$ otros grupos étnicos, al menos allá en Los Ángeles. Pero acá los bichos están en otra cosa. Yo y un montón de gente de mi generación no nos sentimos identificados con la pandilla de hoy, y no tenemos relaciones con la pandilla de hoy. ${ }^{23}$

En lo concerniente a las razones para salir o desistir, en general tienen que ver con el aparecimiento de un íntimo deseo de abandonar la violenciay un estilo de vida que poco o nadallena ya sus expectativas. Empero, un punto neurálgico es la disposición de las estructuras de poder pandilleril para dejar ir a sus "soldados", sobre todo cuando son pandilleros experimentados que aún pueden aportar al grupo. La rigidez de las jerarquías puede restringir severamente las virtudes y bondades de los procesos de cambio personal. Una expandillera lo narra así:

A mí me llamaron los meros, meros. Me tocó ir al penal y abi me interrogaron, y yo les expliqué

23 Entrevista con pandillera retirada (Ciudad Arce, 2016). 
que por mis hijos quería buscar nueva vida. Ellos me pusieron unas tareas, unas cosas que tenía que hacer por la pandilla, y me dijeron que regresara al siguiente año, supongo que para que uno lo piense bien, y ya luego del año me dieron el pase. Me dijeron que podía salirme, pero que no anduviera cagándola porque con la pandilla no se juega, y que me deseaban suerte. ${ }^{24}$

Esto refleja que la desistencia o el retiro no es asequible para cualquier miembro activo. Sólo quienes han cumplido con años de probada lealtad a la pandilla pueden aspirar a un "retiro digno” y sin líos mayores. Y, además, deben mantener algún grado de relación con el grupo y no abjurar de su otrora pertenencia a la estructura. Tienen que saber guardar silencio y adoptar un bajo perfil.

Como símbolo de la alianza vitalicia que el pandillero establece con su agrupación, se marca la piel con tatuajes. Éstos cumplen una función que va más allá de lo decorativo; implican pacto, entrega plena y hay en el fondo de ellos una lógica de membresía imperecedera (Valenzuela et al., 2007). Por lo tanto, los retirados, si bien pueden apartarse de las actividades pandilleriles, no deben borrarse los tatuajes de su cuerpo sin autorización.

Entre los factores que obstaculizan el retiro de las maras o pandillas destacan, según los entrevistados, los problemas económicos $\mathrm{y}$ la marginación social. Para un expandillero, distanciarse de la pandilla supone también alejarse de las actividades que producen algún ingreso, tanto para ellos mismos como para sus familias. League apunta a cubrir ambas

24 Entrevista con pandillera retirada (Ciudad Arce, 2016). necesidades, proporcionando un empleo y un nuevo círculo social de referencia, con base en procesos de conversión espiritual y de cambio de vida. Es más, hay casos en los que distintos miembros de una misma familia están contratados en la "cueva de Adulam".

\section{Yo empiezo a trabajar con los pandilleros a través de sus madres. Como las madres eran operarias, y como yo las conocía a ellas, me enteraba de los problemas que tenian por que sus hijos eran pandilleros. ${ }^{25}$}

Asimismo, la empresa sostiene comunicación y hasta cierta coordinación con pastores evangélicos, los cuales recomiendan a potenciales candidatos para ser empleados. Son una clase de mentores para los pandilleros retirados. Un ejemplo de eso es el vínculo con la Iglesia Elim, de donde han llegado varios exmiembros de pandillas que ahora trabajan en la fábrica. De hecho, una peculiaridad de League es el rasgo "cristo-céntrico" 26 que se proyecta en actividades de integración interpersonal y laboral, lo que fija una suerte de continuum entre la iglesia y el empleo.

La experiencia de League ha llegado al punto de mirar afuera de sus muros. Se ha barajado la idea de desarrollar proyectos habitacionales a gran escala, inclusive. Es el caso de Ciudad Obrera, ubicada a pocos kilómetros de la fábrica. En esta colonia, en asocio con pastores evangélicos, se ejecuta un esfuerzo por incorporar a la empresa a aquellas personas que obtengan su título de bachiller.

25 Entrevista con Gerente General de League (Ciudad Arce, 2016).

26 Entrevista con Gerente General de League (Ciudad Arce, 2016). 
Uno de los problemas más grandes de esa comunidad era que los chicos salían del bachillerato y no encontraban trabajo. Entonces se metian a la pandilla. Por eso decidimos incorporarlos acá. Como una forma, además, de alentar a otros a que sigan estudiando. ${ }^{27}$

Esa conjunción de valores propios del mundo empresarial o de los negocios con un enfoque espiritual y social es una de las características particulares de la iniciativa de League (Soler y Flores, 2016). Gracias a eso se ha podido diseñar un "ambiente protector" para pandilleros retirados, libre de discriminación, lo que ofrece condiciones más apropiadas para acometer la rehabilitación y reinserción (Cruz et al., 2017).

\subsection{Mecanismos de las pandillas mismas}

En esta última sección se entregan dos breves historias de vida de expandilleros que, por rutas disímiles, hallaron la salida de las maras o pandillas. El primero lo consiguió por la vía de alcanzar la veteranía, después de un extenso recorrido pandilleril; el segundo, en cambio, lo hizo por medio de la expulsión y el destierro, producto de conflictos irreconciliables con su grupo.

\subsubsection{Retiro por veteranía: la misión cumplida}

"Igor" nació en un municipio del interior del país en los años 60. Hijo de una familia pobre, migró a Estados Unidos en 1977, con apenas 12 años de edad. Esta familia, a diferencia de muchísimas otras, no emigró debido a la guerra civil, puesto que todavía no había empezado en todo su fragor.

27 Entrevista con Gerente General de League (Ciudad Arce, 2016).
Lo hicieron buscando oportunidades laborales y mejorar su calidad de vida.

El paso por México no era tan peligroso en aquella época e "Igor" recuerda haber viajado en buses durante largas horas. El cruce por la frontera tampoco fue muy complejo, ya que bastó con sobornar a algunos oficiales migratorios para colarse a California. Luego de unas horas más, estaban andando en Los Ángeles.

Era una familia numerosa y con pocos recursos. "Igor" fue inscrito en una escuela de la zona y allí surgieron sus problemas. Muchachos de una pandilla llamada La Raza Loca lo agredieron en reiteradas ocasiones en distintos lugares: dentro de la escuela, camino a casa, en el vecindario. Era una estrategia para ejercer presión y que se uniese a esa pandilla, pero no funcionó con "Igor".

Buscó apoyo en el único grupo que no le marginaría por su procedencia salvadoreña. Se trataba de un estadio incipiente de la MS-13, en el que aún se denominaban Mara Salvatrucha Stoners (MSS). Por su nacionalidad, ingresó con relativa facilidad a una clica cercana a su barrio. A partir de ahí, se relacionó con un buen número de pandilleros y con otras clicas que conformaban una especie de confederación o sistema. La pandilla, aceleradamente, comenzó a apoderarse de territorios, calles e incluso escuelas. A mediados de los 80, la MSS era ya una de las agrupaciones a tener en cuenta en el panorama de las pandillas sureñas.

En aquel entonces, "Igor" llegó a ser líder de su clica y un pandillero prominente. Estuvo involucrado en homicidios y participó en las primeras escaramuzas contra la pandilla Barrio 18. Así lo explica: 
Es que nosotros no teníamos pedo con la 18. En realidad, eran pandillas bien cercanas, pero los problemas empezaron porque nosotros íbamos creciendo mucho y eso a ellos no les gustó nada. El primer enfrentamiento fue en un parque, cerca de Pico. Ahi ya hubo balazos. ${ }^{28}$

Las anécdotas sobre el inicio de las hostilidades entre ambas pandillas son diversas, e "Igor" perteneció a esa generación de fundadores que posicionaron a la MS-13 como un grupo respetable en el entramado cultural de las pandillas californianas.

Estuvo preso varios años por lesiones y portación de arma de fuego. Luego fue deportado a $\mathrm{El}$ Salvador, donde se topó con familiares que no sabían nada de él. No tenía amigos ni trabajo, y su español no era el más fluido. Se encontró con una hermana menor que le dio posada por un tiempo en su casa, situada en una colonia marginal de San Salvador. Allí resolvió organizar una nueva clica con jóvenes de la comunidad.

El primero en ser brincado fue justamente el novio de su hermana; después, se integraron dos adolescentes del vecindario, quienes, a su vez, atrajeron amigos y compañeros de escuela. La clica creció. "Igor" cuenta, asimismo, cómo se conectó con otros deportados que habían hecho lo mismo:

Nos reuniamos frente al Mercado Modelo. Abi nos juntábamos y hablábamos, haciamos negocios, abi la pasábamos bien. Algunos andaban ya robando o en contrabando $y$ embandados [incorporados en bandas], otros no, sólo controlando quizá algún territorio o incluso nada, sólo por encontrarse con los homeboys. ${ }^{29}$

La guerra callejera que tenían en California con la pandilla Barrio 18 fue trasplantada a El Salvador, y acá tomó vuelo, con niveles más violentos. "Igor" continuó encabezando su clica. Formó a incontables pandilleros y estableció lazos con clicas alrededor del país. No obstante, a principios de la década de los años 2000 las dinámicas de las maras o pandillas se habían modificado. Otros liderazgos se perfilaban tanto en la MS-13 como en el Barrio 18. La violencia de las nuevas generaciones era desconocida para muchos deportados, como "Igor", quienes paulatinamente se alejaron de las actividades pandilleriles y delegaron sus responsabilidades en miembros más jóvenes.

"Igor" decidió por cuenta propia inscribirse en cursos que impartía el Instituto Técnico Ricaldone (ITR). Se capacitó como electricista, plomero y mecánico de estructuras metálicas. Montó una modesta empresa, de la cual es el director y principal obrero. Así sostiene a su familia. Sus vínculos con la MS-13 se limitan a cuestiones muy concretas, como pequeños favores recíprocos con la clica que él mismo erigió. A veces le venden herramientas robadas a buen precio o repuestos para su vehículo. Empero, él considera que esa es otra pandilla, ya no la que conoció en los años 80 y 90 . En ocasiones se reúne con otros viejos pandilleros y rememoran sus tiempos en las calles y en las cárceles, beben cerveza y recuerdan a los muertos. Si se le pregunta directamente por su 
actual estatus en la pandilla, "Igor" responde que es un "jubilado de la mara”. ${ }^{30}$

\subsubsection{Faltista, yardero o marquero: la expulsión de un pandillero}

Miguel Ángel Tobar se unió a una pandillita a los 12 años de edad, llamada Gauchos Locos 13. Era un grupo compuesto por niños del municipio de Atiquizaya. Entró a esa pandilla como reacción a los problemas que en su familia habían escalado al grado de poner en riesgo su vida.

El núcleo familiar de Miguel vivía y laboraba en una finca de café, en donde el caporal o mayordomo se había amancebado con su hermana adolescente. La madre de Miguel consentía esta relación, puesto que le generaba ciertos beneficios a la hora de obtener trabajo dentro de la finca. Pero el mayordomo era un hombre violento, sobre todo cuando se emborrachaba. Empezó a maltratar a la hermana de Miguel, a su madre y a él mismo.

Para entonces, ya de 12 años, se determinó a atacar un día al caporal. Lo esperó un 31 de diciembre, aguardó a que bebiera hasta tambalearse y lo siguió a un camino solitario y obscuro. Le golpeó la cabeza con una roca y le robó un revólver. Luego tuvo que huir. Así es como se enrola en la Gauchos Locos 13.

Durante los primeros años de la década de los 90, en ese municipio operaban varias pandillas, pero se contentaban con armar reyertas con intercambios de pedradas y otras manifestaciones violentas que, de ordinario, no tenían conclusiones letales.

30 Entrevista con pandillero retirado (San Salvador, 2012).
No obstante, a mediados de los 90 fue deportado a El Salvador José Antonio Terán, un miembro de la MS-13 conocido como "el Veneno", de la clica Fulton Locos Salvatrucha (FLS) del Valle de San Fernando en Los Ángeles. Este hombre había formado parte de la Guardia Nacional (GN) en los años 80, y al llegar al Valle de San Fernando fundó, junto con otros salvadoreños, la FLS. Como suceso extraño en la MS-13, ya en Atiquizaya no clonó su clica de origen, sino que se dedicó a conformar otra: la Hollywood Locos Salvatrucha (HLS).

De entrada, sometieron a los chicos de las pequeñas pandillas barriales que existían, como la Gauchos Locos 13, y posteriormente comenzaron a moldear una estructura sólida, con identidad propia. Miguel fue bautizado con el apodo -o taca- de "el Enano", por su baja estatura. Al cabo de unos años, y después de lidiar con correrías y salvajes incursiones en contra de la pandilla Barrio 18 de territorios aledaños, se sumó al círculo de líderes de la clica HLS, presidido por José Antonio Terán, quien se había cambiado a sí mismo el alias por el de "Chepe Furia".

El amorío entre la MS-13 y Miguel llegó a su fin cuando su hermano, quien también pertenecía a la pandilla, fue asesinado a manos de sus mismos compañeros. Miguel se enteró de esto y empezó una cacería de los hechores. Los mató uno por uno, siempre simulando ataques por parte del Barrio 18. De manera espaciada fue asesinando, oculta y secretamente, a cada uno de los 5 pandilleros que estuvieron involucrados en el homicidio de su hermano, sin dejar jamás de hacer méritos para la pandilla. Se anotaba en todas las acciones en terreno enemigo, en 
ocasiones para vengar a homeboys que él mismo había matado. Tenía una doble vida.

De esa forma, subió al puesto número 3 en el orden jerárquico de la clica, se hizo de armas de buena calidad, administró un negocio propio de marihuana e incluso reemplazó su sobrenombre por el de "el Niño". A simple vista, parece un apodo inofensivo; sin embargo, se lo autoimpuso luego de descuartizar a un hombre y sacarle el corazón por el estómago, después de lo cual, según recuerda, sentenció: “;Ve!, una operación como para sacar un niño le hice... De hoy en adelante voy a ser 'el Niño de Hollywood". ${ }^{31}$

"El Niño" y "Chepe Furia” se volvieron pandilleros temibles; y la clica HLS, dirigida por el segundo, desarrolló vasos comunicantes con narcotraficantes locales, en particular con el llamado "Cártel de Texis". Terán se adhirió a esa estructura criminal básicamente asumiendo tareas de sicariato, tumbes de droga y amenazas a competidores. Miguel era el encargado por excelencia de materializar esas funciones.

Pese a su alto rango, los miembros de la HLS ataron cabos y dedujeron que Miguel había asesinado a otros compañeros de la clica, y decidieron matarlo. Le tendieron una trampa y lo encaminaron a un lugar dominado por el Barrio 18, pero Miguel había detectado la artimaña y, antes de que activaran la emboscada, mató a quien lo guiaba. No le quedaron muchas opciones. Sabía que tenía a su pandilla encima, y a la pandilla contraria también. Desde ese instante, "el Niño" era considerado un "peseta", un traidor y enemigo a muerte.

31 Entrevista con pandillero retirado (Atiquizaya, 2013).
Un investigador de la PNC había seguido los pasos de Miguel y conocía lo que sucedía al interior de la clica HLS, y aprovechó el momento. Un día visitó a Miguel en su guarida, en son de paz, y habló con él. Le ofreció la protección de la FGR si cooperaba con ellos. Miguel aceptó y durante 3 años fue un informante protegido en el proceso contra José Antonio Terán, así como en casi medio centenar de casos en contra de pandilleros de su clica y de otras. A raíz de las confesiones de "el Niño de Hollywood", muchos de esos pandilleros pasarán el resto de sus vidas en la cárcel.

Cuando terminaron las audiencias y los juicios, la FGR le suspendió la protección, el pírrico estipendio y la casucha que le habían dado a Miguel para que la habitara con su pareja $y$ sus dos hijas. Se fueron a vivir a las afueras del pueblo, en el monte, pero hasta ahílo persiguió su pasado. Esos cerros yermos estaban en territorio del Barrio 18 y Miguel les debía muertos. Lo asechaban y atacaban con frecuencia. Miguel se defendía con una escopeta hechiza, que él había fabricado, y con un machete filoso. Luego de un tiempo, logró asentarse en casa de su madre, en un cantón en el que la presencia de las pandillas no era fuerte. Comenzó a organizar un grupo con muchachos de la zona para protegerse. Levantó un pequeño negocio de venta de marihuana y con eso subsistió por 2 años.

La MS-13, no obstante, estaba al tanto de su rol como "testigo criteriado", y "Chepe Furia" había girado órdenes de asesinarle. "El Niño" era un "peseta" por partida doble: había matado a compañeros pandilleros y, además, se había convertido en colaborador de las autoridades. En noviembre de 2014, dos sujetos a bordo de 
un mototaxi le dispararon 6 veces en una vereda del municipio de San Lorenzo. El caso está archivado y no hubo capturas.

\section{A modo de conclusión}

Como colofón, se lista un paquete condensado de las conclusiones más relevantes:

- A lo largo de la posguerra, el Gobierno de El Salvador ha ajustado el discurso oficial sobre las maras o pandillas, con mayor fuerza en el ámbito de la represión y el control del delito. La inclusión de ese fenómeno social y delictivo en las políticas públicas de seguridad ciudadana ha sido lenta y paulatina. En cuanto a la rehabilitación y reinserción de pandilleros, empero, el cambio de discurso no ha sido tan expreso, y menos patente todavía es la modificación en las prácticas institucionales en esa línea.

- La sociedad civil ha efectuado notables esfuerzos en materia de reinserción de miembros de pandillas. Existen iniciativas de muy distinto signo que resultan prometedoras. Sin embargo, al no haber suficiente claridad técnica acerca de las implicaciones conceptuales y metodológicas de esta tarea, se advierte una cierta atomización y desarticulación de las acciones emprendidas por actores no gubernamentales.

- Para efectos de implementar programas o proyectos de rehabilitación y reinserción, es preciso distinguir si un pandillero está en grado de llegar a ser "calmado", "retirado" o "peseta", porque cada una de esas categorías plantea escenarios y prospectivas diferentes.
- Distanciarse de las maras o pandillas y sus dinámicas violentas no tiene que ver, única y exclusivamente, con declarar el deseo de desistir. Si se quiere salir de estos grupos con vida, y aun así mantener buenas relaciones con la pandilla de origen, en general es necesario pasar por un proceso en el que los líderes locales evalúan la trayectoria del solicitante, la avalan y luego establecen una suerte de "cuota" o acciones que la persona debe cumplir antes de autorizarle que se aleje de la estructura. En tal sentido, el retiro no sería más que el eslabón final de una larga cadena de roles que los miembros de pandillas cumplen como tales. Los pandilleros retirados son sometidos a constante vigilancia o supervisión, al menos durante un tiempo que puede ser variable, ya que incluso en ese punto tienen reglas que observar y acatar.

- Lo anterior guarda relación también con la posición que ostentan los pandilleros dentro de las estructuras de sus grupos, lo que determina sus posibilidades de abandonarlos. Tal parece que las 7 posiciones jerárquicas fundamentales, de manera ascendente, son: Paro, Observación, Chequeo, Homeboy ${ }^{32}$, Corredor de clica, Corredor de programa $^{33}$ y Ranflero. Los primeros 3 puestos o niveles, en realidad, los ocupan aspirantes a brincarse, es decir que en rigor aún no son pandilleros activos.

- Los miembros de pandillas que suelen ponderar la opción de retirarse de sus agrupaciones son, normalmente, personas

32 Otros sinónimos son: Homie, Activo o Soldado.

33 Conjunto de clicas. 
que han ido madurando, ya han asumido compromisos personales y familiares $y$, por ende, han transformado su visión de la vida, la cual dista de la actitud de temeridad o de kamikaze que tienen los más jóvenes y que resumen en la frase: "En la vida loca hasta la maldita muerte."

- En síntesis, tres grandes aspectos posibilitan y condicionan la desistencia de las maras o pandillas: 1) Un proceso individual de maduración personal que da paso a una forma distinta de verse a sí mismos y su pertenencia al grupo; 2) Un cambio en la situación con respecto del propio grupo, que habilita al pandillero a replantear los términos de la relación con su pandilla, y 3) Un contexto social y comunitario que reciba sin discriminación a los exmiembros de maras o pandillas. ${ }^{34}$

- Experiencias como las de las iglesias, en especial las evangélicas, han tenido un rol clave en la rehabilitación y reinserción de expandilleros. Las iniciativas de las iglesias han contado con la virtud de llenar carencias psicológicas, afectivas y sociales decisivas, no necesariamente las de orden económico o material, lo que permite "reinventarse". En todo caso, para evitar eventuales consecuencias para exmiembros, es crucial hacer valer el edicto pandilleril: "No se juega con Dios ni con la pandilla.”

- Conviene visualizar que entre las iglesias también existen diferencias importantes.

34 Recuperado de: https://informatvx.com/la-pandilla-es-un-grupoque-ejerce-un-poder-totalizante-en-las-comunidades/
Las hay, al menos, de tres tipos: 1) "De puertas adentro" (intimistas y desconectadas de las realidades social y comunitaria); 2) "De puertas abiertas" (vinculadas con las comunidades en las que se localizan e interesadas en el desarrollo social), y 3) "De fachada" (falsas iglesias que sirven como cobertura para pandilleros activos).

- Asimismo, casos como el de League Collegiate Outfitters están en sintonía con esa lógica de favorecer la reconstrucción de la autoimagen personal y la creación de nuevas redes sociales de apoyo para expandilleros, amén de los empleos que se brindan.

- Esta idea es consistente con estudios que señalan que entre los valladares que más restringen la intención de dejar las pandillas destacan: la presencia territorial de los grupos mismos de maras o pandillas, la falta de habilidades y oportunidades laborales, la amenaza constante de violencia y la discriminación social (Cruz et al., 2017).

\section{Bibliografía}

Aguilar, J. (2016). El Rol del Ejército en la Seguridad Interna en El Salvador: Lo Excepcional Convertido en Permanente. Re-conceptualización de la Violencia en el Triángulo Norte. Abordaje de la Seguridad en los Paises del Norte de Centroamérica desde una Visión Democrática. El Salvador: Fundación Heinrich Böll-México, Centroamérica y E1 Caribe. Pp. 61-83.

Amaya, L.E. \& Martínez, J.J. "Sureños en E1 Salvador: Un Acercamiento Antropológico a las Pandillas de Deportados", Revista Realidad 
y Reflexión, No 39 (enero-junio 2014). E1 Salvador: UFG Editores.

Amaya, L.E. \& Martínez, J.J. "Escisión al Interior de la Pandilla Barrio 18 en El Salvador: Una Mirada Antropológica”, Revista Policía y Seguridad Pública, No 7 (enero-junio 2015). El Salvador: CINC-ANSP.

Bastián, J.P. "Protestantismo Popular y Política en Guatemala y Nicaragua", Revista Mexicana de Sociología, No 3 (julio-septiembre 1986). México: Universidad Nacional Autónoma de México.

Blatchford, C. (2011). Mafia Chicana: Memorias de René "Boxer" Enríquez. México: Ediciones B.

Brenneman, R. (2012). Homies and Hermanos: God and Gangs in Central America. United States: Oxford University Press.

Buscaglia, E. (2013). La Paradoja de la Represión. La Impotencia del Estado ante el Crimen Organizado. Picar Piedra. Iniciativas Ciudadanas Frente a la Violencia. México: Heinrich Böll Stiftung-México, Centroamérica y el Caribe. Pp. 17-25.

Consejo Nacional de Seguridad Ciudadana y Convivencia. (2015). Plan El Salvador Seguro. El Salvador: Consejo Nacional de Seguridad Ciudadana y Convivencia.

Consejo Nacional de Seguridad Pública. (1996). Elementos Básicos para una Estrategia de Seguridad Pública. El Salvador: Consejo Nacional de Seguridad Pública.

Consejo Nacional de Seguridad Pública. (1998).
La Prevención de la Delincuencia Juvenil en El Salvador: Hacia la Formulación de una Politica Social Integral. E1 Salvador: Consejo Nacional de Seguridad Pública.

Cruz, J.M. \& Portillo, N. (1998). Solidaridad y Violencia en las Pandillas del Gran San Salvador: Más Allá de la Vida Loca. El Salvador: UCA Editores.

Cruz, J.M. (2006). Maras y Pandilla en Centroamérica: Las Respuestas de la Sociedad Civil Organizada. Volumen IV. El Salvador: UCA Editores.

Cruz, J.M. \& Carranza, M. (2006). Pandillas y Políticas Públicas: El Caso de El Salvador. Juventudes, Violencia y Exclusión: Desafíos para las Políticas Públicas. Guatemala: Magna Torres ediciones. Pp. 133-176.

Cruz, J.M., Rosen, J., Amaya, L.E. \& Vorobyeva, Y. (2017) The New Face of Street Gangs: The Gang Phenomenon in El Salvador. United States: Florida International University.

Foley, M.W. “¿Qué Entendemos por 'Desarrollo'?", Realidad: Revista de Ciencias Sociales y Humanidades, No 48 (noviembrediciembre 1995). El Salvador: UCA Editores.

Fundación de Estudios para la Aplicación del Derecho. (2018). Propuesta para una Ley Especial de Prevención de la Violencia: Una Tarea Impostergable. E1 Salvador: FESPAD Ediciones.

Gobierno de El Salvador. (2013). Estrategia Nacional de Prevención de la Violencia. E1 Salvador: Gobierno de E1 Salvador. 
Huezo Mixco, L.R. (2013). A la Espera del Reino Milenial: Misiones de Fe, Fundamentalismo Religioso y su Visión de lo Social. El Salvador 1893-1932. De las Misiones de Fe al Neopentecostalismo: Génesis y Evolución del Protestantismo Salvadoreño, desde el Siglo XIX hasta el Presente. E1 Salvador: Dirección Nacional de Investigaciones en Cultura y Arte, de la Secretaría de Cultura de la Presidencia. Pp. 95-147.

Instituto Universitario de Opinión Pública. (2018). Evaluación del País a Finales de 2017 y Perspectivas Electorales para 2018. El Salvador: IUDOP-UCA.

International Crisis Group. (2017). Política y Violencia Perpetua en El Salvador. Bélgica: Oficina principal International Crisis Group.

Katz, C.M. \& Amaya, L.E. (2015). La Tregua entre Pandillas como una Forma de Intervención sobre la Violencia: Implicaciones en Políticas y Prácticas. E1 Salvador: FUNDE.

Lara, C.B. (1996). Iglesias Evangélicas y Conflicto Político en El Salvador. La Etnografía de Mesoamérica Meridional y el Área Circuncaribe. II Coloquio Paul Kirchhoff. México: Instituto de Investigaciones Antropológicas, Universidad Nacional Autónoma de México. Pp. 340-360.

Lara, C.B. (2006). La Población Indígena de Santo Domingo de Guzmán: Cambio y Continuidad Sociocultural. El Salvador: Dirección de Publicaciones e Impresos, Consejo Nacional para la Cultura y el Arte.

Martínez, J.J. (2013). Ver, Oir, Callar: En las
Profundidades de una Pandilla Salvadoreña. E1 Salvador: Aura ediciones.

Mendoza, J.C. \& Pacheco, J.V. (2015). La Aplicación del Criterio de Oportunidad en el Proceso Penal Especializado (Tesis). El Salvador: Universidad de El Salvador.

Ministerio de Justicia y Seguridad Pública. (2012). Politica Nacional de Justicia, Seguridad Pública y Convivencia. El Salvador: Gobierno de El Salvador.

Ministerio de Justicia y Seguridad Pública. (2015). Politica Nacional de Justicia, Seguridad Pública y Convivencia 2014-2019. El Salvador: Gobierno de El Salvador.

Monroy, D.E. (1996). Cien Años de Presencia Evangélica en El Salvador. El Salvador: Sociedad Bíblica de El Salvador.

Montes, S. (1979). El Compadrazgo: Una Estructura de Poder en El Salvador. E1 Salvador: UCA Editores.

Moodie, E. (2012). El Salvador in the Aftermath of Peace: Crime, Uncertainty, and the Transition to Democracy. United States: University of Pennsylvania Press.

Moodie, E. \& Martínez, J.J. (2015). En las Llamas de la Paz: La Quema de un Microbús y los Significados de la Violencia. Violencia en Tiempos de Paz: Conflictividady Criminalización en El Salvador. E1 Salvador: Dirección Nacional de Investigaciones en Cultura y Arte, de la Secretaría de Cultura de la Presidencia. Pp. 147-185. 
Santacruz, M.L. \& Concha-Eastman, A. (2001). Vega, M. (2013). Emergiendo del Conflicto: Barrio Adentro: La Solidaridad Violenta de las Los Medios de Comunicación Protestantes Pandillas. E1 Salvador: UCA Editores.

Smutt, M. \& Miranda, J.L. (1998). El Fenómeno de las Pandillas en El Salvador. El Salvador: FLACSO-Programa El Salvador.

Soler, C. \& Flores, M. "League: Una Empresa que Revoluciona el Management”, Revista Realidad Empresarial, No 1 (marzo 2016). E1 Salvador: Talleres Gráficos UCA. Evangélicos y su Aporte en la Formación del Espacio Público. De las Misiones de Fe al Neopentecostalismo: Génesis y Evolución del Protestantismo Salvadoreño, desde el Siglo XIX hasta el Presente. El Salvador: Dirección Nacional de Investigaciones en Cultura y Arte, de la Secretaría de Cultura de la Presidencia. Pp. 149-186.

Wolf,S."El Salvador's Pandilleros Calmados:The Challenges of Contesting Mano Dura through Valenzuela, J.M., Nateras, A. \& Reguillo, R. Peer Rehabilitation and Empowerment", (2007).Las Maras: Identidades Juveniles al Limite. Bulletin of Latin American Research, No 2 (abril México: Universidad Autónoma Metropolitana 2012). United States: Wiley

Unidad Iztapalapa, El Colegio de la Frontera

Norte, Casa Juan Pablos. 